Review Article

\title{
A Meta-Analysis: Whether Repetitive Transcranial Magnetic Stimulation Improves Dysfunction Caused by Stroke with Lower Limb Spasticity
}

\author{
Yu Liu $\mathbb{D}^{1}{ }^{1}$ Hong Li $\mathbb{D}$, ${ }^{1}$ Jun Zhang $\mathbb{D}^{2}, 2$ Qing-qing Zhao $\mathbb{D}^{1,3}$ Hao-nan Mei $\mathbb{D}^{1,3}$ \\ and Jiang $M a \mathbb{C}^{1}$ \\ ${ }^{1}$ Department of Rehabilitation Medicine, Shijiazhuang People's Hospital, Shijiazhuang 050030, Hebei, China \\ ${ }^{2}$ Rehabilitation District of Taihe Hospital, Shiyan 442000, Hubei, China \\ ${ }^{3}$ School of Nursing and Rehabilitation, North China University of Science and Technology, Tangshan 063210, Hebei, China \\ Correspondence should be addressed to Jiang Ma; majiangtutor@sina.com
}

Received 10 June 2021; Accepted 21 October 2021; Published 28 November 2021

Academic Editor: Feng Zhang

Copyright ( $) 2021$ Yu Liu et al. This is an open access article distributed under the Creative Commons Attribution License, which permits unrestricted use, distribution, and reproduction in any medium, provided the original work is properly cited.

Objective. To evaluate the efficacy of repetitive transcranial magnetic stimulation (rTMS) in improving lower limb spasticity after stroke. Methods. The PubMed, Web of Science, Cochrane Library, EMBASE, China National Knowledge Infrastructure (CNKI), China Biology Medicine (CBM) disc, China Science and Technology Journal Database (VIP), and Wanfang databases were searched online from their inception to May 2021 for randomized controlled trials (RCTs) involving repetitive transcranial magnetic stimulation for lower extremity spasticity after stroke. Valid data were extracted from the included literature, and the quality evaluation was conducted with the Cochrane Handbook for Systematic Reviews of Interventions along with the Physiotherapy Evidence Database scale (PE-Dro scale). The data that met the quality requirements were systematically analysed using Review Manager 5.4 software. Results. A total of 554 patients from seven articles (nine studies) were quantitatively analysed. Outcomes included the Modified Ashworth Scale (MAS), Fugl-Meyer Assessment of Lower Extremity (FMA-LE), Modified Barthel Index (MBI), and Timed Up and Go (TUG), measured as the effect of rTMS compared with controls conditions after treatment. The systematic review showed that rTMS reduced MAS and increased MBI scores, respectively $(\mathrm{SMD}=-0.24,95 \%$ CI $[-0.45,-0.03], P=0.02 ; \mathrm{MD}=6.14,95 \% \mathrm{CI}[-3.93,8.35], P<0.00001)$, compared with control conditions. Low-frequency $\mathrm{rTMS}$ (LF-rTMS) significantly improved FMA-LE scores (SMD $=0.32,95 \% \mathrm{CI}[0.13,0.51], P=0.001)$. However, there was no significant difference in FMA-LE scores when using high-frequency rTMS (HF-rTMS) $(P>0.1)$ and in TUG times $(P>0.1)$ between the treatment and control groups. Conclusions. rTMS was effective in improving spasticity and activities of daily living. LF-rTMS has positive clinical effects on enhancing motor function in patients who experience lower extremity spasticity after stroke. To better validate the above conclusions, more multicentre, high-quality, and double-blind randomized controlled trials are needed.

\section{Introduction}

Stroke is a common disease worldwide and causes serious disabilities for patients. More than two-thirds of stroke survivors develop poststroke sequelae that involve impairment of motor function, balance, gait, and activities of daily living $[1,2]$. Poststroke spasticity (PSS) is a common motor dysfunction after stroke that clinically manifests as increased muscle tone, positive pathological signs, and tendon hyperreflexia [3], with a prevalence from $4 \%$ to $42.6 \%$ [2].
Current management of poststroke spasticity has shown that although drug therapy (such as botulinum toxin injection, oral baclofen, dantrolene, sodium, and tizanidine) is effective for improving spasticity and widely used in clinical practice, it had side effects and produced unsatisfied clinical effects such as muscle weakness [4]. Nondrug therapy, such as neuromuscular electrical stimulation and physical therapy, temporarily relieved poststroke spasticity and motor dysfunction. However, some of these interventions demand active participants to become involved, and the duration of 
the efficacy was relatively short $[5,6]$. rTMS has been gradually applied in the clinical treatment of poststroke dysfunction due to its noninvasiveness and safety on the basis of conventional treatment of stroke sequelae. But most of the research focused on motor dysfunction, cognitive disorder, aphasia, and so on. There are few studies on the application of rTMS in poststroke spasticity, and the mechanism is unclear. What is more, rTMS has a significant impact on public acceptance due to the relatively high clinical costs and being excluded in the health insurance in some cities [7-9]. A recent meta-analysis explored the use of rTMS in stroke patients. Two meta-analyses published by McIntyre et al. [10] and Peng et al. [11] analysed the effect of rTMS in the rehabilitation of spasticity after stroke. However, they did not include RCTs for the treatment of lower limb spasticity after stroke, and some new RCTs have been published since then. Moreover, the efficacy of repetitive transcranial magnetic stimulation in improving lower limb spasticity after stroke remains unknown. As a result, the purpose of this study was to perform a systematic review of RCTs that explored the efficacy of rTMS in treating patients with lower limb spasticity after stroke.

\section{Methods}

2.1. Literature Search Strategy. We performed a search in the PubMed, Web of Science, Cochrane Library, EMBASE, CNKI, CBM, VIP, and Wanfang databases published up to May 2021. The search terms were "stroke" OR "hemiplegia" OR "cerebrovascular accident" OR "ischemic stroke" OR "hemorrhagic stroke" OR "CVA" OR "apoplexy" AND "repetitive transcranial magnetic stimulation" OR "rTMS" OR "transcranial magnetic stimulation" OR "TMS" AND "spasticity" AND "lower limb" OR "lower extremity".

2.2. Inclusion and Exclusion Criteria. The relevant articles were selected based on the following eligibility criteria: (1) the involved patients were clinically diagnosed with lower limb spasticity after stroke by relevant examinations; (2) the experimental group used rTMS and traditional physical therapy, while the control group underwent traditional physical therapy plus sham rTMS (or only with traditional physical therapy); (3) the outcome measures included the MAS, FMA-LE, MBI, and TUG; and (4) the included articles were RCTs.

Articles meeting with the following criteria were excluded: (1) total sample size of fewer than 10 participants in each study; (2) study with incomplete data; (3) meta-analysis, case report, literature review, guidelines, dissertation, and others; and (4) non-RCTs.

2.3. Literature Screening and Data Extraction. Two researchers independently searched and screened the literature based on the above search strategy and removed the studies that did not meet the predefined criteria by reading the abstracts and full texts. Any inconsistencies between the two authors were resolved by discussion or in consultation with the third author. The following data were extracted: study characteristics (authors, year of publication, study design, sample sizes, age, and course of disease) and intervention details (intervention measures, treatment time, stimulated sites, treatment parameters, and outcome measures).

2.4. Literature Quality Evaluation. The quality of the included articles was evaluated by two authors using the Cochrane Handbook for Systematic Reviews of Interventions [12] and PE-Dro [13]. In cases of disagreement, a third person made the final decision. Three levels (level A, level B, and level C) were used to rank the quality of each study when using the former method [12]. Regarding the PE-Dro, 0-3 points indicated low quality, 4-7 points indicated medium quality, and 8-11 indicated high-quality [14].

2.5. Data Synthesis and Statistical Methods. The outcomes in both the treatment and control groups after the intervention period were extracted. The results were shown by the histogram in one study [15], and we estimated the results based on the $X$ and $Y$ axes and the corresponding parameters. A sixpoint scale $\left(0,1,1^{+}, 2,3\right.$, and 4$)$ was denoted as the MAS scale [16]. To quantify the score for analysis, we calculated $1^{+}$as 1.5 . If the results were not presented as the means and standard deviations, we calculated the original data using SPSS 25.0 [17] or the method of Wan et al. [18]. The data from the first phase for both groups were extracted in randomized controlled crossover studies $[15,19,20]$. If the variable between two groups in an article was only rTMS, we divided the one article into two studies $[17,21]$. Quantitative analysis was performed using Review Manager version 5.4 by two authors. Concerning the continuous variables (excluding $H_{\max } / M_{\max }$ ), the mean difference $(\mathrm{MD})$ or the standardized mean difference (SMD) with $95 \%$ CI were calculated for the outcome. The heterogeneity among the included studies was assessed by the $\chi^{2}$ test and Higgins $I^{2}$ values. If there was clear heterogeneity $\left(I^{2}>50 \%\right.$ or $\left.P<0.1\right)$, a random effects model was used. Otherwise, a fixed effects model was applied.

\section{Results}

3.1. Characteristics of the Studies. A total of 113 entries were retrieved from Chinese and English databases, including 33 in Chinese and 80 in English (Figure 1); 50 duplicates were removed through EndNote X9; and 63 articles were screened. Then, 21 were excluded because the article type was not a clinical trial. A total of 42 full-text studies were obtained for eligibility. Then, 35 studies were rejected: 25 due to the population, 4 owing to the intervention, 3 because of the study design, and 3 because of the assessed outcome. Finally, seven articles with a total of 554 patients $[15,17,19-23]$ were included. Two articles had two separate data sets $[17,21]$, and the others had one data set each. Table 1 shows the characteristics of the included articles. All the included studies were randomized controlled trials with quality level $\mathrm{B}$, and three of them were crossover trials $[15,19,20]$. The risk of bias of the included RCT is shown in Figure 2. The total score on the PE-Dro was 51, with an 


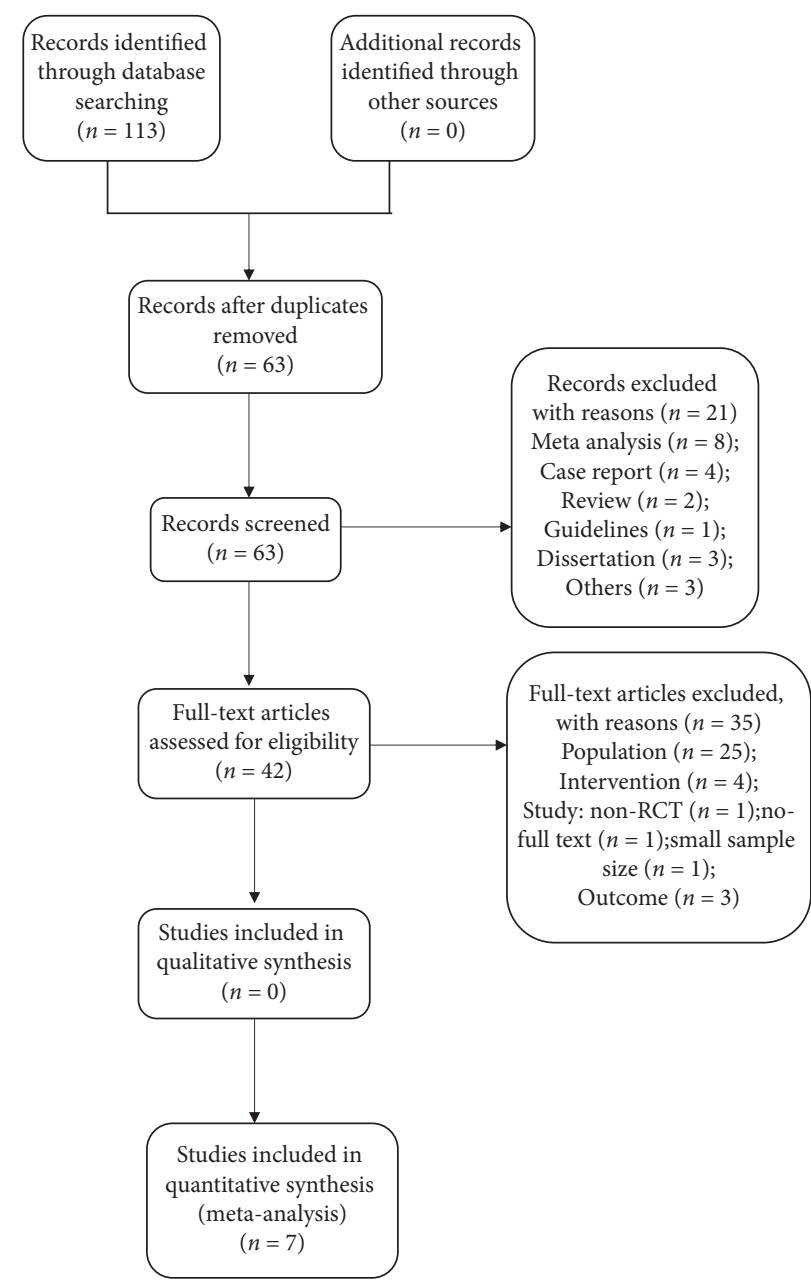

FIgURE 1: Flow diagram of study selection.

TABLe 1: Characteristics of included articles.

\begin{tabular}{|c|c|c|c|c|c|c|c|c|c|}
\hline $\begin{array}{l}\text { Author/ } \\
\text { year }\end{array}$ & $\begin{array}{l}\text { Sample } \\
\text { size }\end{array}$ & Mean age (y) & $\begin{array}{c}\text { Course of } \\
\text { disease }(\mathrm{m}) \\
\text { Treatment/cont }\end{array}$ & $\begin{array}{l}\text { Intervention } \\
\text { ol }\end{array}$ & $\begin{array}{c}\text { Treatment } \\
\text { duration }\end{array}$ & Stimulated site & $\begin{array}{l}\text { Treatment } \\
\text { parameters }\end{array}$ & RCT type & Outcome \\
\hline $\begin{array}{l}\text { Chieffo } \\
\text { et al., } \\
2020 \text { [19] }\end{array}$ & $6 / 6$ & $\begin{array}{c}58.67 \pm 10.33 / \\
61.17 \pm 8.70\end{array}$ & $\begin{array}{c}41.50 \pm 26.77 / \\
41.00 \pm 26.54\end{array}$ & $\begin{array}{c}r+c l \\
\operatorname{sham}+c\end{array}$ & $\begin{array}{l}15 \mathrm{~min} / \mathrm{day} \\
11 \text { sessions }\end{array}$ & $\begin{array}{l}\text { Bilateral leg } \\
\text { motor cortex }\end{array}$ & $\begin{array}{c}20 \mathrm{~Hz}, \\
80 \%-90 \% \\
\text { RMT, } \\
\text { H-coil }\end{array}$ & $\begin{array}{c}\text { Crossover } \\
\text { trial }\end{array}$ & $\begin{array}{c}\text { FMA-LE, } \\
\text { MAS, 10- } \\
\text { MT, } \\
6 \mathrm{MWT}\end{array}$ \\
\hline $\begin{array}{l}\text { Rastgoo } \\
\text { et al., } \\
2016[15]\end{array}$ & $7 / 7$ & $\begin{array}{c}54.60 \pm 11.75 / \\
49.70 \pm 11.00\end{array}$ & $\begin{array}{c}30.2 \pm 18.3 / \\
27.4 \pm 20.1\end{array}$ & $r /$ sham & $\begin{array}{c}20 \mathrm{~min} / \text { day, } \\
5 \text { days }\end{array}$ & $\begin{array}{l}\text { Leg motor } \\
\text { cortex of the } \\
\text { unaffected } \\
\text { hemisphere }\end{array}$ & $\begin{array}{c}1 \mathrm{~Hz}, 90 \% \\
\text { RMT, } \\
\text { eight coil }\end{array}$ & $\begin{array}{c}\text { Crossover } \\
\text { trial }\end{array}$ & $\begin{array}{c}\text { MMAS, } \\
\text { FMA-LE, } \\
H_{\max } / \\
M_{\max } \\
\text { TUG }\end{array}$ \\
\hline $\begin{array}{l}\text { Yijie, } \\
2018 \text { [20] }\end{array}$ & $70 / 70$ & $\begin{array}{c}55.20 \pm 11.50 / \\
51.30 \pm 12.10\end{array}$ & $\begin{array}{c}31.60 \pm 11.5 / \\
51.3 \pm 12.1\end{array}$ & $\begin{array}{c}r+R / \\
\text { sham }+R\end{array}$ & $\begin{array}{c}20 \mathrm{~min} / \text { day } \\
5 \text { days }\end{array}$ & $\begin{array}{l}\text { Contralateral } \\
\text { cerebral cortex }\end{array}$ & $\begin{array}{c}1 \mathrm{~Hz}, 90 \% \\
\text { RMT, } \\
\text { eight coil }\end{array}$ & $\begin{array}{c}\text { Crossover } \\
\text { trial }\end{array}$ & $\begin{array}{c}\text { MAS, } \\
\text { FMA-LE, } \\
H_{\max } / \\
M_{\max } \\
\text { TUG }\end{array}$ \\
\hline $\begin{array}{l}\text { Jing et al., } \\
2018 \text { [21] }\end{array}$ & $24 / 24$ & $\begin{array}{c}56.55 \pm 13.11 / \\
57.33 \pm 12.00\end{array}$ & $\begin{array}{c}3.58 \pm 2.44 / \\
4.01 \pm 2.89 \\
\text { days }\end{array}$ & $r+R / R$ & $\begin{array}{l}15 \mathrm{~min} / \text { day, } \\
1 \mathrm{month}\end{array}$ & $\begin{array}{l}\text { Primary motor } \\
\text { cortex of the } \\
\text { unaffected } \\
\text { hemisphere }\end{array}$ & $\begin{array}{c}1 \mathrm{~Hz}, 90 \% \\
\mathrm{RMT}\end{array}$ & $\begin{array}{c}\text { Factorial } \\
\text { trial }\end{array}$ & $\begin{array}{c}\text { MAS, } \\
\text { FMA-LE, } \\
\text { MBI, BBS }\end{array}$ \\
\hline
\end{tabular}


TABle 1: Continued.

\begin{tabular}{|c|c|c|c|c|c|c|c|c|c|}
\hline $\begin{array}{l}\text { Author/ } \\
\text { year }\end{array}$ & $\begin{array}{l}\text { Sample } \\
\text { size }\end{array}$ & Mean age (y) & $\begin{array}{c}\text { Course of } \\
\text { disease }(\mathrm{m}) \\
\text { Treatment/cont }\end{array}$ & $\begin{array}{l}\text { Intervention } \\
\text { rol }\end{array}$ & $\begin{array}{l}\text { Treatment } \\
\text { duration }\end{array}$ & Stimulated site & $\begin{array}{l}\text { Treatment } \\
\text { parameters }\end{array}$ & RCT type & Outcome \\
\hline $\begin{array}{l}\text { Jing et al., } \\
2018 \text { [21] }\end{array}$ & $24 / 24$ & $\begin{array}{c}56.21 \pm 11.68 / \\
55.93 \pm 13.88\end{array}$ & $\begin{array}{c}4.33 \pm 2.57 / \\
4.41 \pm 2.69 \\
\text { days }\end{array}$ & $\begin{array}{c}r+B+R / \\
B+R\end{array}$ & $\begin{array}{l}15 \mathrm{~min} / \mathrm{day} \\
1 \mathrm{month}\end{array}$ & $\begin{array}{l}\text { Primary motor } \\
\text { cortex of the } \\
\text { unaffected } \\
\text { hemisphere }\end{array}$ & $\begin{array}{c}1 \mathrm{~Hz}, 90 \% \\
\mathrm{RMT}\end{array}$ & $\begin{array}{l}\text { Factorial } \\
\text { trial }\end{array}$ & $\begin{array}{c}\text { MAS, } \\
\text { FMA-LE, } \\
\text { MBI, BBS }\end{array}$ \\
\hline $\begin{array}{l}\text { Yang } \\
\text { et al., } \\
2015 \text { [22] }\end{array}$ & $60 / 60$ & $\begin{array}{c}58.7 \pm 3.5 / \\
59.2 \pm 3.3\end{array}$ & $\begin{array}{c}4.6 \pm 1.2 / \\
4.3 \pm 1.4\end{array}$ & $r+R / r$ & $\begin{array}{c}15 \mathrm{~min} / \text { day, } \\
5 \text { days/ } \\
\text { week, } 8 \\
\text { weeks }\end{array}$ & $\begin{array}{l}\text { M1 of the } \\
\text { affected } \\
\text { hemisphere }\end{array}$ & $\begin{array}{c}2 \mathrm{~Hz}, 90 \% \\
\text { RMT } \\
\text { butterfly } \\
\text { shaped } \\
\text { coils }\end{array}$ & $\begin{array}{c}\text { Parallel } \\
\text { trial }\end{array}$ & $\begin{array}{c}\text { FMA, } \\
\text { FAC, CSI, } \\
\text { 10-MT }\end{array}$ \\
\hline $\begin{array}{l}\text { Hong } \\
\text { et al., } \\
2016 \text { [17] }\end{array}$ & $20 / 20$ & $\begin{array}{c}62.18 \pm 13.66 / \\
61.23 \pm 14.24\end{array}$ & $\begin{array}{c}3.98 \pm 2.05 / \\
4.61 \pm 2.50 \\
\text { days }\end{array}$ & $r+R / R$ & $\begin{array}{c}20 \mathrm{~min} / \text { day, } \\
6 \text { days/ } \\
\text { week, } 4 \\
\text { weeks }\end{array}$ & $\begin{array}{l}\text { Primary motor } \\
\text { cortex of the } \\
\text { unaffected } \\
\text { hemisphere }\end{array}$ & $\begin{array}{c}1 \mathrm{~Hz}, 90 \% \\
\text { RMT } \\
\text { circular coil }\end{array}$ & $\begin{array}{l}\text { Factorial } \\
\text { trial }\end{array}$ & $\begin{array}{c}\text { MAS, } \\
\text { FMA-LE, } \\
\text { MBI }\end{array}$ \\
\hline $\begin{array}{l}\text { Hong } \\
\text { et al., } \\
2016 \text { [17] }\end{array}$ & $20 / 20$ & $\begin{array}{c}61.99 \pm 15.02 / \\
60.89 \pm 15.16\end{array}$ & $\begin{array}{c}4.02 \pm 3.17 / \\
4.35 \pm 3.28 \\
\text { days }\end{array}$ & $\begin{array}{c}r+B+R / \\
r+B\end{array}$ & $\begin{array}{c}20 \mathrm{~min} / \text { day, } \\
6 \text { days/ } \\
\text { week, } 4 \\
\text { weeks }\end{array}$ & $\begin{array}{l}\text { Primary motor } \\
\text { cortex of the } \\
\text { unaffected } \\
\text { hemisphere }\end{array}$ & $\begin{array}{c}1 \mathrm{~Hz}, 90 \% \\
\text { RMT } \\
\text { circular coil }\end{array}$ & $\begin{array}{l}\text { Parallel } \\
\text { trial }\end{array}$ & $\begin{array}{c}\text { MAS, } \\
\text { FMA-LE, } \\
\text { MBI }\end{array}$ \\
\hline $\begin{array}{l}\text { Huayao } \\
\text { et al., } \\
2019 \text { [23] }\end{array}$ & $47 / 45$ & $\begin{array}{l}43.33 \pm 9.18 / \\
44.33 \pm 9.94\end{array}$ & & $\begin{array}{c}r+F / \\
\operatorname{sham}+F\end{array}$ & $\begin{array}{c}20 \mathrm{~min} / \text { day, } \\
5 \text { days/ } \\
\text { week, } 4 \\
\text { weeks }\end{array}$ & $\begin{array}{l}\text { M1 of the } \\
\text { affected brain } \\
\text { hemisphere }\end{array}$ & $1 \mathrm{~Hz}$ & $\begin{array}{c}\text { Parallel } \\
\text { trial }\end{array}$ & $\begin{array}{l}\text { MAS, } \\
\text { FMA-LE, } \\
\text { MEP }\end{array}$ \\
\hline
\end{tabular}

$r$ : rehabilitation; sham: sham rTMS; c: cycling; B: BTX-A; R: rehabilitation; F: FES (functional electrical stimulation).

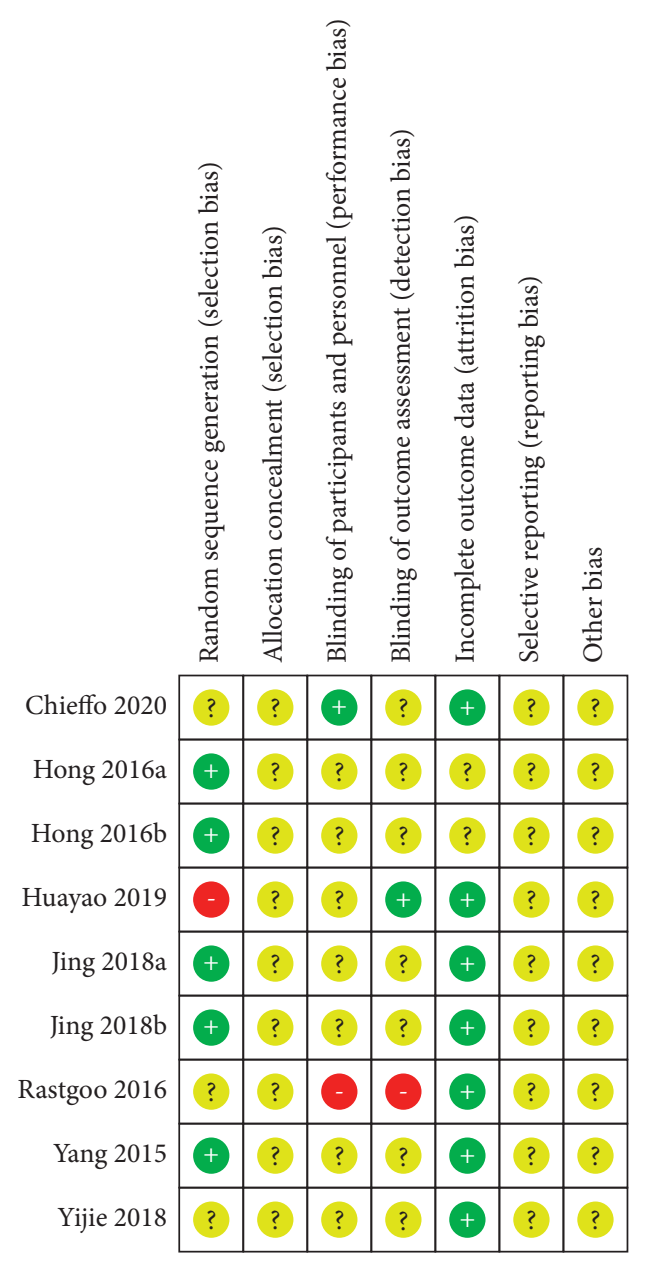

(a)

FIgURE 2: Continued. 


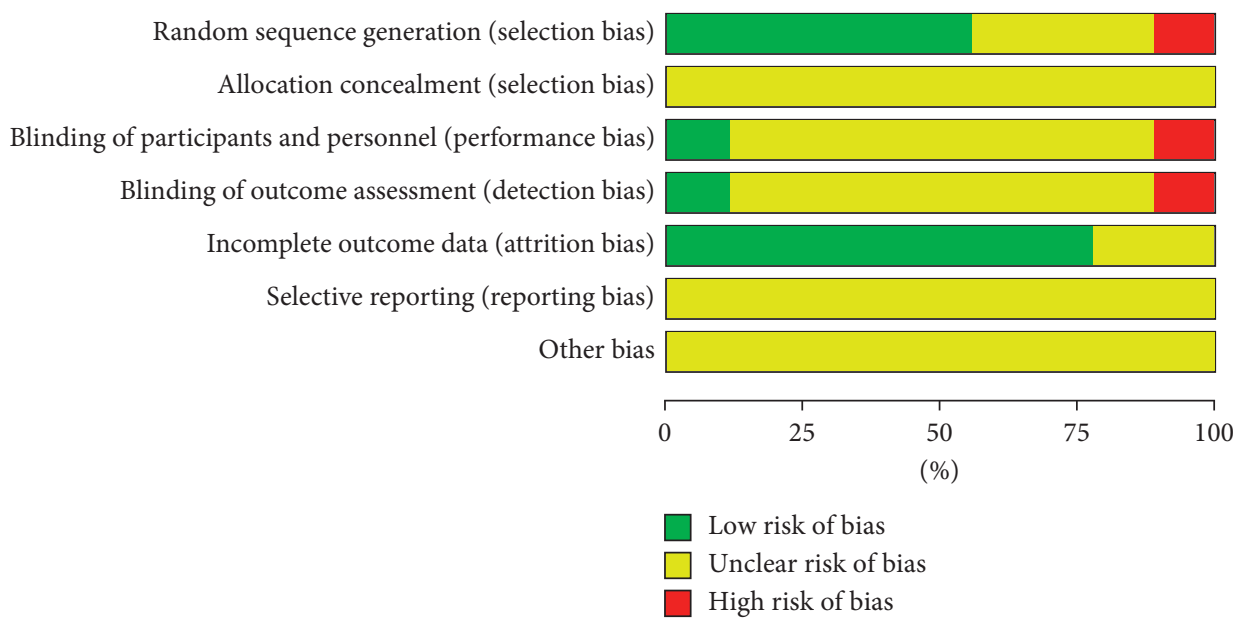

(b)

FIgURE 2: (a) Risk of bias graph. (b) Risk of bias summary.

average of 7.29. Two articles were of high quality [17, 19], and five were of medium quality (Table 2).

\subsection{Effects of rTMS on Spasticity of the Lower Limbs in Stroke Patients}

3.2.1. MAS. Five articles (seven studies) $[17,19,21,23]$ with 420 patients were included. The forest plot (Figure 3(a)) shows that statistical heterogeneity was not observed $\left(I^{2}=44 \%, P=0.10\right)$. We used the fixed effects model because heterogeneity was not observed after two studies were $[19,21]$ excluded through sensitivity analysis $\left(I^{2}=0 \%\right.$, $P=0.78)$. The meta-analysis showed that rTMS had a significant beneficial effect on MAS scores in patients with lower limb spasticity after stroke $(\mathrm{SMD}=-0.24,95 \% \mathrm{CI}$ $[-0.45,0.03], P=0.02$ ) (Figure 3(b)).

\subsection{Effects of rTMS on Spasticity of the Lower Limbs in Stroke Patients}

3.3.1. FMA. A total of seven articles (nine studies) with 554 patients $[15,17,19-23]$ presented effects on the FMA. Subgroup analysis based on low- and high-frequency indicated seven studies with LF-rTMS and two with HF-rTMS. The difference between groups among those using lowfrequency rTMS showed a statistically significant effect on FMA scores $(\mathrm{SMD}=0.32,95 \%$ CI $[0.13,0.51], P=0.001)$ with no statistical heterogeneity $\left(I^{2}=1 \%, P=0.42\right)$. There was no statistical significance between the two groups in the studies using high-frequency rTMS $(P=0.72)$ (Figure 4).

\subsection{Effects of rTMS on Spasticity of the Lower Limbs in Stroke Patients}

3.4.1. MBI. Two articles (four studies) $[17,21]$ with 176 patients assessed this outcome. The random effects model was used with $I^{2}=40 \%$ and $P=0.17$ (Figure 5(a)). Jing was the source of the heterogeneity after sensitivity analysis (Figure 5(b)). We found that there was a significant difference between the two groups ( $\mathrm{MD}=6.14,95 \% \mathrm{CI}[3.93$, 8.35], $P<0.00001)$.

\subsection{Effects of rTMS on Spasticity of the Lower Limbs in Stroke Patients}

3.5.1. TUG Scores. Two studies $[15,20]$ showed that rTMS did not have a significant effect on MBI scores in the patients with lower limb spasticity (Figure 6).

3.6. Others. The electrophysiological index $H_{\max } / M_{\max }$ was described in two studies $[15,20]$ and showed that the index decreased in the treatment group without a significant difference compared with the control group.

The included articles reported adverse effects except for Hong [17]. Three studies [15, 20, 21] showed that patients had good tolerance to LF-rTMS in their studies. Chieffo et al. [19] reported transitory dizziness and muscle twitches in the shoulders of three patients, and they subsequently completed the remaining treatment after the intensity was decreased to $80 \%$ RMT. In another study, the patients had muscle pain and fatigue symptoms that were relieved after two to three days [21]. Huayao et al. [23] reported adverse effects without a significant difference between the two groups. In the treatment group, transitory headache was found in two patients, which diminished after suspension of the treatment [22].

\section{Discussion}

Velocity-dependent increases in muscle tone, hyperexcitable stretch reflexes, and hyperreflexia tendon jerks are often described as features of spasticity that appear in patients with stroke [24]. The reason for muscle spasticity in stroke patients is the hyperreflexia of the stretch reflex from the spine. The excitability and inhibitory imbalance of spinal 
TABLe 2: PE-Dro scale of the included study.

\begin{tabular}{|c|c|c|c|c|c|c|c|c|c|c|c|c|}
\hline Study & Item 1 & Item 2 & Item 3 & Item 4 & Item 5 & Item 6 & Item 7 & Item 8 & Item 9 & Item 10 & Item 11 & Total \\
\hline Chieffo et al., 2020 [19] & 1 & 1 & 0 & 1 & 1 & 1 & 1 & 1 & 0 & 1 & 1 & 9 \\
\hline Rastgoo et al., 2016 [15] & 1 & 1 & 0 & 1 & 1 & 0 & 0 & 0 & 1 & 1 & 1 & 7 \\
\hline Yijie, 2018 [20] & 1 & 0 & 0 & 1 & 1 & 0 & 0 & 1 & 1 & 0 & 1 & 6 \\
\hline Jing et al., 2018 [21] & 1 & 1 & 0 & 1 & 1 & 0 & 0 & 1 & 1 & 1 & 1 & 7 \\
\hline Yang et al., 2015 [22] & 1 & 1 & 0 & 1 & 0 & 0 & 0 & 1 & 1 & 1 & 1 & 7 \\
\hline Hong et al., 2016 [17] & 1 & 1 & 0 & 1 & 0 & 0 & 1 & 1 & 1 & 1 & 1 & 8 \\
\hline Huayao et al., 2019 [23] & 1 & 0 & 0 & 1 & 0 & 0 & 1 & 1 & 1 & 1 & 1 & 7 \\
\hline
\end{tabular}

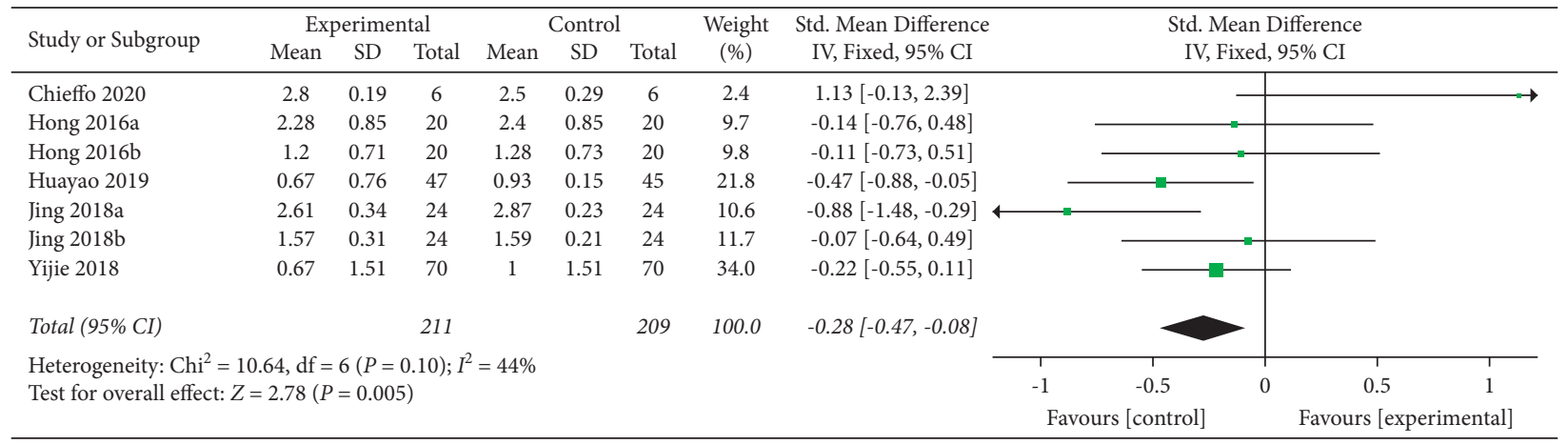

(a)

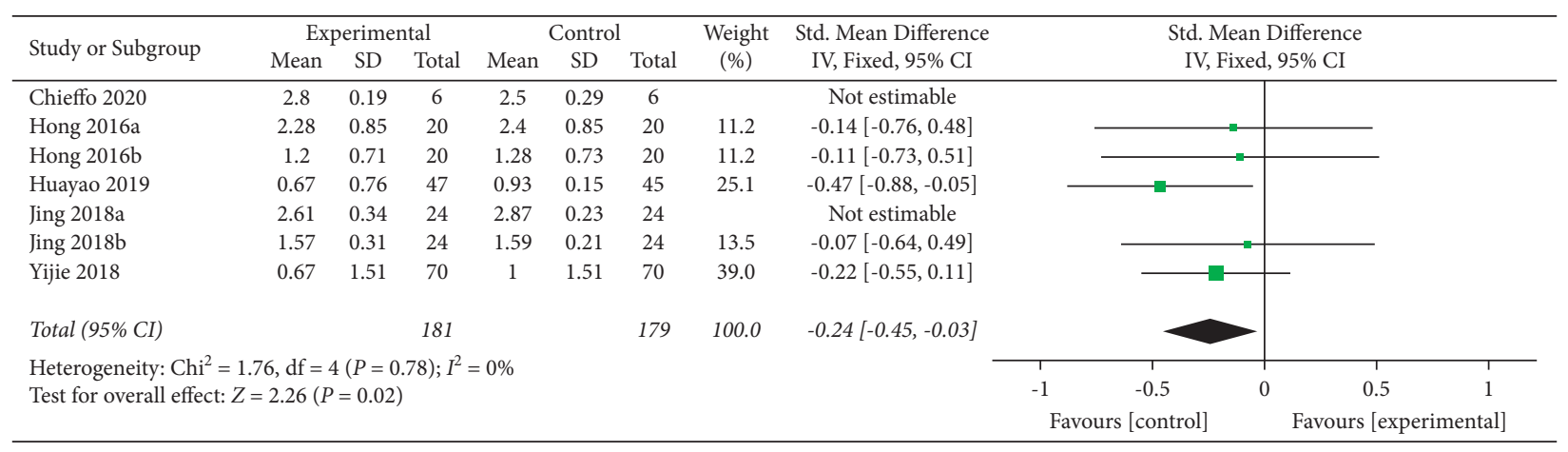

(b)

FIgURe 3: (a) Forest plot for MAS scores. (b) Forest plot for MAS scores when excluding two studies with high sensitivity.

descending fibres was considered the main cause of hyperreflexia of the stretch reflex. The disorder presents with high excitability of the reticular spine [25]. In addition, there has also been evidence that the vestibular spinal cord was less inhibitory [26], which reduces the inhibition of the spinal cord. Stroke patients with lower limb spasticity generally manifest hip adduction, knee extension, and ankle plantar flexion impacting the recovery of motor function and gait [27].

At present, the conventional treatment for lower limb spasticity after stroke includes drugs, motor therapy, and neuromuscular electrical stimulation [6]. However, the effect of conventional rehabilitation is limited. Thus some ways of complementary and alternative medicine are needed. Previous studies have shown that rTMS can be used to treat patients with lower limb spasticity after stroke with different results and unclear mechanisms. Naghdi et al. [28] reported that improvements in ankle plantar flexor and knee extensor spasticity were significant, but $H_{\max } / M_{\max }$ showed no statistical improvement after five consecutive LF-rTMS sessions. Terreaux et al. [29] showed that $1 \mathrm{~Hz}$ rTMS reduced the excitability of the ankle plantar flexor reflex without modifying clinical signs of spasticity, but there was no change during $10-\mathrm{Hz}$ rTMS. Because these studies were a nonrandomized controlled trial [28] or had a small sample size [29], our research group performed a systematic analysis including the most recent randomized controlled trials with more participants to further increase the quality of the included studies.

The results indicated that rTMS was effective in improving lower limb spasticity and activities of daily living; LF-rTMS had a positive influence on enhancing motor function in patients who experienced lower extremity spasticity after stroke, whereas HF-rTMS did not have a 


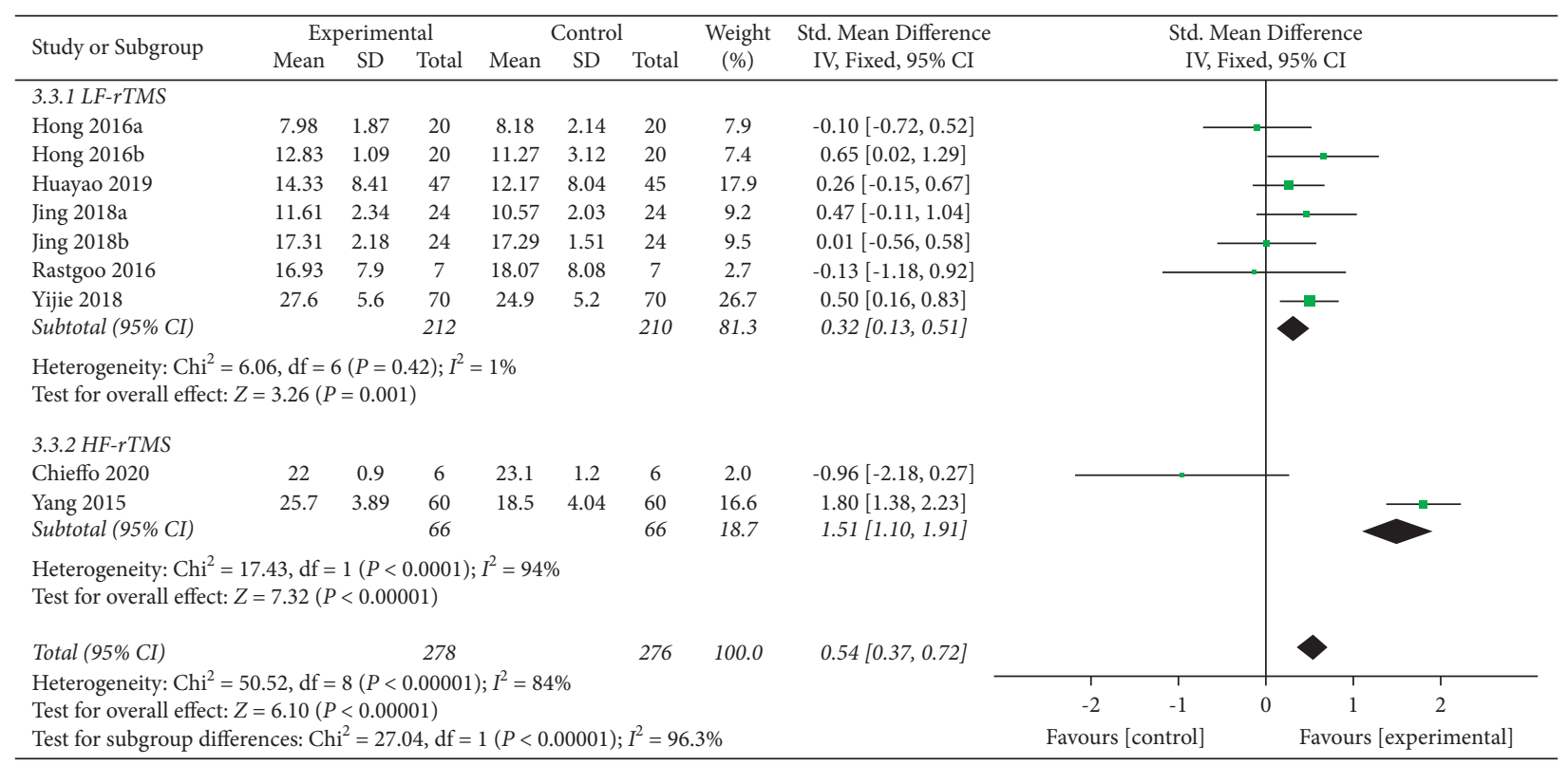

Figure 4: Forest plot of FMA.

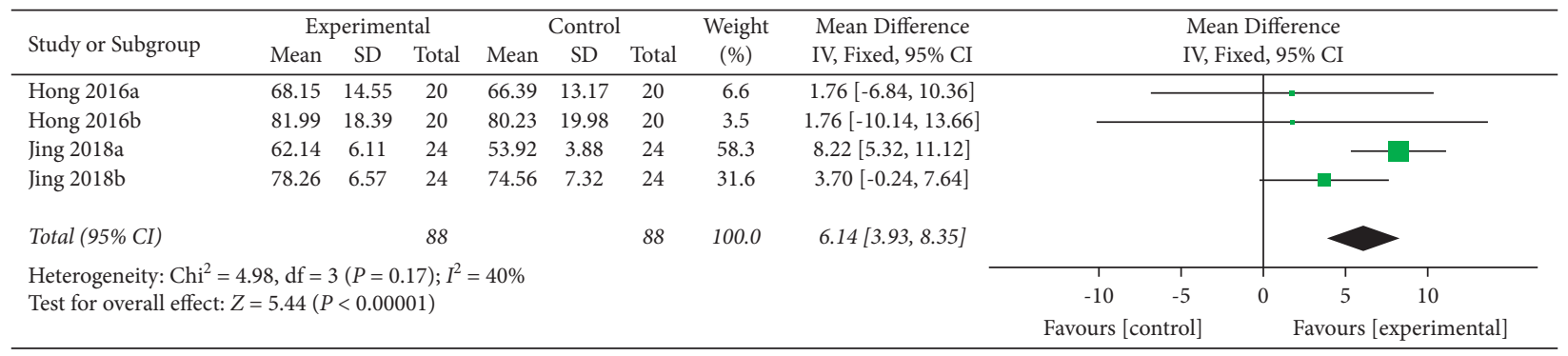

(a)

\begin{tabular}{|c|c|c|c|c|c|c|c|c|c|c|c|c|}
\hline \multirow{2}{*}{ Study or Subgroup } & \multicolumn{3}{|c|}{ Experimental } & \multicolumn{3}{|c|}{ Control } & \multirow{2}{*}{$\begin{array}{c}\text { Weight } \\
(\%)\end{array}$} & \multirow{2}{*}{$\begin{array}{l}\text { Mean Difference } \\
\text { IV, Fixed, 95\% CI }\end{array}$} & \multirow{2}{*}{\multicolumn{4}{|c|}{$\begin{array}{l}\text { Mean Difference } \\
\text { IV, Fixed, 95\% CI }\end{array}$}} \\
\hline & Mean & SD & Total & Mean & $\mathrm{SD}$ & Total & & & & & & \\
\hline Hong 2016a & 68.15 & 14.55 & 20 & 66.39 & 13.17 & 20 & 15.9 & $1.76[-6.84,10.36]$ & & & & - \\
\hline Hong 2016b & 81.99 & 18.39 & 20 & 80.23 & 19.98 & 20 & 8.3 & $1.76[-10.14,13.66]$ & & & & \\
\hline Jing 2018a & 62.14 & 6.11 & 24 & 53.92 & 3.88 & 24 & & Not estimable & & & & \\
\hline Jing $2018 b$ & 78.26 & 6.57 & 24 & 74.56 & 7.32 & 24 & 75.8 & $3.70[-0.24,7.64]$ & & & & \\
\hline Total $(95 \%$ CI) & & & 64 & & & 64 & 100.0 & $3.23[-0.20,6.66]$ & & & & \\
\hline \multirow{2}{*}{\multicolumn{9}{|c|}{$\begin{array}{l}\text { Heterogeneity: } \mathrm{Chi}^{2}=0.23, \mathrm{df}=2(P=0.89) ; I^{2}=0 \% \\
\text { Test for overall effect: } Z=1.85(P=0.06)\end{array}$}} & $\begin{array}{c}1 \\
-10\end{array}$ & -5 & $\begin{array}{ll}1 & 1 \\
0 & 5\end{array}$ & 10 \\
\hline & & & & & & & & & \multicolumn{4}{|c|}{ Favours [control $] \quad$ Favours [experimental $]$} \\
\hline
\end{tabular}

(b)

Figure 5: (a) Forest plot for MBI scores. (b) Forest plot for MBI scores after removing one study.

\begin{tabular}{|c|c|c|c|c|c|c|c|c|c|c|c|c|c|}
\hline \multirow{3}{*}{$\begin{array}{l}\text { Study or Subgroup } \\
\text { Rastgoo } 2016\end{array}$} & \multicolumn{3}{|c|}{ Experimental } & \multicolumn{3}{|c|}{ Control } & \multirow{2}{*}{$\begin{array}{l}\text { Weight } \\
(\%)\end{array}$} & \multirow{2}{*}{$\begin{array}{l}\text { Std. Mean Difference } \\
\text { IV, Fixed, 95\% CI }\end{array}$} & \multirow{2}{*}{\multicolumn{5}{|c|}{$\begin{array}{l}\text { Std. Mean Difference } \\
\text { IV, Fixed, 95\% CI }\end{array}$}} \\
\hline & Mean & $\mathrm{SD}$ & Total & Mean & $\mathrm{SD}$ & Total & & & & & & & \\
\hline & 15.5 & 27.1 & 7 & 15.73 & 28.29 & 7 & 9.1 & $-0.01[-1.06,1.04]$ & & & & & - \\
\hline Yijie 2018 & 23.7 & 20.6 & 70 & 24 & 21.5 & 70 & 90.9 & $-0.01[-0.35,0.32]$ & & & & & \\
\hline Total (95\% CI) & & & 77 & & & 77 & 100.0 & $-0.01[-0.33,0.30]$ & & & & & \\
\hline \multirow{2}{*}{\multicolumn{9}{|c|}{$\begin{array}{l}\text { Heterogeneity: } \mathrm{Chi}^{2}=0.00, \mathrm{df}=1(P=0.99) ; I \\
\text { Test for overall effect: } Z=0.08(P=0.93)\end{array}$}} & -1 & $\begin{array}{ll} \\
-0.5\end{array}$ & 0 & & 1 \\
\hline & & & & & & & & & \multicolumn{5}{|c|}{$\begin{array}{c}0.5 \\
\text { Favours [experimental] }\end{array}$} \\
\hline
\end{tabular}


significant effect on motor function. Furthermore, rTMS did not have an additional significant effect on TUG times or $H_{\max } / M_{\max }$. McIntyre et al. [10] performed a systematic review regarding the use of rTMS in patients with spasticity after stroke and discovered that rTMS improved spasticity in the elbow, wrist, and finger flexors in uncontrolled pre-post studies, whereas there was no significant influence on spasticity in the wrist in two RCTs. Another meta-analysis by $\mathrm{Xu}$ et al. [11] was published in 2020 and reported no benefits on the use of rTMS for upper limb spasticity after stroke, which was different from our research.

Sensitivity analyses of the included studies found that the cause of high bias of risk in Jing and Yan [21] may have been the short duration of treatment and the poor baseline condition of the patients. Rastgoo [15] and Yijie [20] reported that the reason why gait function was improved in both the treatment and control groups after the treatment was that patients were similar regarding TUG measures (TUG refers to the time it takes for the subject to stand up after hearing the instruction, walk straight for three meters, and return to the sitting position with the quickest speed [30]). Few of them had barriers to walking. Electrophysiological changes $\left(H_{\max } / M_{\max }\right)$ were [31] not accompanied by clinical improvement in spasticity in Rastgoo et al. [15], which was similar to the result of Dos Santos et al. [32]. $H_{\max } / M_{\max }$, which has been related to an increase in muscle tone in spasticity to a certain extent, is the ratio of the maximum amplitude of $H$ reflexion and $M$ wave recorded by surface electromyography. $H_{\max } / M_{\max }$ does not completely reflect the excitability of neurons with measurement of error, and $H_{\text {SLP }} / M_{\text {SLP }}$ was proposed as a better outcome [33]. $H_{\text {SLP }} / M_{\text {SLP }}$ (the ratio of the slope of $H$ and $M$-waves) was more sensitive to represent the excitability of motor neuron of the anterior horn of the spinal cord [34]. In addition, the reasons for unsynchronized changes were that the treatment times of rTMS were short with only five sessions and the relationship between $H_{\max } / M_{\max }$ and MAS is not exact, which may not change with the change of MAS [35]. There were no serious adverse effects reported during the process of treatment. Five studies $[15,17,20-22]$ followed up patients after therapy, and Jing [21] reported that FMA, MAS, and MBI scores were significantly different between the treatment and control groups after the 12-month follow-up. rTMS is based on the principle of electromagnetic induction and produces changes at the stimulated site and transsynaptically in distant cortical regions. Sustained physiological effects were a feature of rTMS, namely, long-term potential and long-term depression [36], while neuromuscular electrical stimulation had a short duration of the therapeutic effect without the above features [37], as previously mentioned.

The mechanism by which rTMS improves spasticity is not clear. There are two commonly used models of rTMS: (1) a high-frequency $(>1 \mathrm{~Hz})$ facilitatory mode, which is applied to the affected brain region to increase cortical excitability and thus reduce spasticity and improve upper limb motor function, and (2) a low-frequency $(\leq 1 \mathrm{~Hz})$ inhibitory mode, which decreases excitability in the unaffected hemisphere and therefore reduces inhibition from the contralateral hemisphere to the ipsilateral hemisphere $[31,38,39]$. We concluded from the subgroup analysis that the LF-rTMS group showed a significant influence on lower limb motor function, while there were no benefits of HF-rTMS. The better therapy between high- or low-frequency stimulation has been controversial. Based on the guidelines written by Lefaucheur et al. [40], LF-rTMS over the contralesional hemisphere promoted poststroke recovery of motor function in chronic stroke patients. Owing to the limited studies we included, the curative effect of HF-rTMS remains to be discussed. Guo et al. [41] reported that the reorganization of the motor network was found with both HF-rTMS and LFrTMS, and both improved motor recovery; HF-rTMS had more positive effects on the functional connectivity reorganization of the ipsilesional motor network. In addition to stimulation frequency, the stimulation parameters of rTMS also include stimulation duration and intensity. Further studies about parameters selection that make rTMS optimally effective need to be conducted.

The stimulated site included in this study was the leg motor cortex, which is associated with a deep position that is located on the inner side of the anterior central gyrus under a thick skull [42]. To ensure that rTMS has a good effect on the rehabilitation of patients with lower limb spasticity after stroke, the requirement for stimulation depth was quite high. In addition to the intensity of the rTMS used in the adopted studies (i.e., 80\%-90\% RMT), the rTMS coil itself also played a pivotal role in the effects of lower limb spasticity after stroke. The types of coils were different across studies included in our analysis: Rastgoo et al. [15] and Yijie [20] used a figure-8-shaped coil with higher focal stimulation and less white matter penetration. Chieffo et al. [19] found that the reason that the use of an $\mathrm{H}$ coil with deeper stimulation did not improve spasticity and walking function was that rTMS combined with cycling did not influence the functional networks involved in the coordination of gait and skilled walking. This was also considered the reason for the heterogeneity observed in this meta-analysis. Although the circular coil had deep penetration, the short duration of treatment with unconcentrated stimulation was the reason for the lack of improvements in lower limb MAS scores [17].

The limitations of this study are as follows: first, the risk of bias was slightly high. The three crossover trials included in this paper only contributed data from the first stage to this analysis; thus, the testing power was reduced. In addition, the affected region of the brain is a factor that influences spasticity after stroke, and subgroup analyses of the main muscle groups in the context of lower extremity spasticity were not conducted. The MAS, FMA, and MBI are semiquantitative indicators, and the evaluators may have introduced subjectivity when assessing them. More large-scale and high-quality randomized controlled trials with targeted and precise quantitative indicators as outcomes are expected in the future.

In summary, rTMS was effective in improving spasticity and activities of daily living in patients with lower limb spasticity after stroke. LF-rTMS had a positive effect on enhancing motor function. 


\section{Data Availability}

All the data supporting this systematic review and metaanalysis are included in this study.

\section{Disclosure}

Yu Liu and Hong Li are equal contributors and co-first authors.

\section{Conflicts of Interest}

The authors declare no conflicts of interest.

\section{Acknowledgments}

This study was funded by the S\&T Program of Hebei (2037727D).

\section{Authors' Contributions}

Yu Liu and Hong Li designed the work, analysed the data, and drafted the manuscript. Jun Zhang and Qing-qing Zhao screened the literature. Nan-Hao Mei assisted in screening the literature. Jiang Ma revised the work and agreed to be accountable for all aspects of the work.

\section{References}

[1] S. L. Paul, V. K. Srikanth, and A. G. Thrift, "The large and growing burden of stroke," Current Drug Targets, vol. 8, no. 7, pp. 786-793, 2007.

[2] J. Wissel, A. Manack, and M. Brainin, "Toward an epidemiology of poststroke spasticity," Neurology, vol. 80, no. 3, Supplement 2, p. S13, 2013.

[3] S. Pundik, J. McCabe, M. Skelly, C. Tatsuoka, and J. J. Daly, "Association of spasticity and motor dysfunction in chronic stroke," Annals of Physical and Rehabilitation Medicine, vol. 62, no. 6, pp. 397-402, 2019.

[4] N. Foley, S. Pereira, K. Salter et al., "Treatment with botulinum toxin improves upper-extremity function post stroke: a systematic review and meta-analysis," Archives of Physical Medicine and Rehabilitation, vol. 94, no. 5, pp. 977-989, 2013.

[5] A. Chail, R. K. Saini, P. S. Bhat, K. Srivastava, and V. Chauhan, "Transcranial magnetic stimulation: a review of its evolution and current applications," Industrial Psychiatry Journal, vol. 27, no. 2, pp. 172-180, 2018.

[6] C. J. Winstein, J. Stein, R. Arena et al., "Guidelines for adult stroke rehabilitation and recovery: a guideline for healthcare professionals from the American heart association/American stroke association," Stroke, vol. 47, no. 6, pp. e98-e169, 2016.

[7] F. Moslemi Haghighi, A. Kordi Yoosefinejad, M. Razeghi, A. Shariat, Z. Bagheri, and K. Rezaei, "The effect of highfrequency repetitive transcranial magnetic stimulation on functional indices of affected upper limb in patients with subacute stroke," Journal of Biomedical Physics and Engineering, vol. 11, no. 2, pp. 175-184, 2021.

[8] A. Dionísio, I. C. Duarte, M. Patrício, and M. Castelo-Branco, "The use of repetitive transcranial magnetic stimulation for stroke rehabilitation: a systematic review," Journal of Stroke and Cerebrovascular Diseases, vol. 27, no. 1, pp. 1-31, 2018.

[9] F. Fisicaro, G. Lanza, A. A. Grasso et al., "Repetitive transcranial magnetic stimulation in stroke rehabilitation: review of the current evidence and pitfalls," Therapeutic Advances in Neurological Disorders, vol. 12, pp. 1756286419878317-1756286419878322, 2019.

[10] A. McIntyre, M. Mirkowski, S. Thompson, A. M. Burhan, T. Miller, and R. Teasell, "A systematic review and metaanalysis on the use of repetitive transcranial magnetic stimulation for spasticity poststroke," $P M \& R$, vol. 10, no. 3, pp. 293-302, 2018.

[11] P. Xu, Y. Huang, J. Wang et al., "Repetitive transcranial magnetic stimulation as an alternative therapy for stroke with spasticity: a systematic review and meta-analysis," Journal of Neurology, vol. 268, pp. 817-832, Article ID 10058-4, 2020.

[12] J. P. T. Higgins, D. G. Altman, P. C. Gotzsche et al., "The Cochrane Collaboration's tool for assessing risk of bias in randomised trials," BMJ, vol. 343, p. d5928, 2011.

[13] S. K. Bhogal, R. W. Teasell, N. C. Foley, and M. R. Speechley, "The PEDro scale provides a more comprehensive measure of methodological quality than the Jadad scale in stroke rehabilitation literature," Journal of Clinical Epidemiology, vol. 58, no. 7, pp. 668-673, 2005.

[14] L. Harvey, R. Herbert, and J. Crosbie, "Does stretching induce lasting increases in joint ROM? a systematic review," Physiotherapy Research International, vol. 7, no. 1, pp. 1-13, 2010.

[15] M. Rastgoo, S. Naghdi, N. Nakhostin Ansari et al., "Effects of repetitive transcranial magnetic stimulation on lower extremity spasticity and motor function in stroke patients," Disability \& Rehabilitation, vol. 38, no. 19, pp. 1918-1926, 2016.

[16] A. B. Meseguer-Henarejos, J. Sánchez-Meca, J. A. López-Pina, and R. Carles-Hernández, "Inter-and intra-rater reliability of the Modified Ashworth Scale: a systematic review and metaanalysis," European Journal of Physical and Rehabilitation Medicine, vol. 54, no. 4, pp. 576-590, 2017.

[17] W. Hong, Y. Hua, M. Xiang et al., "The effect of botulinum toxin type A combined with repetitive transcranial magnetic stimulation on spasticity of lower limbs in stroke patients," Chinese Journal of Rehabilitation Medicine, vol. 31, no. 9, pp. 936-940, 2016.

[18] X. Wan, W. Wang, J. Liu, and T. Tong, "Estimating the sample mean and standard deviation from the sample size, median, range and/or interquartile range," BMC Medical Research Methodology, vol. 14, no. 1, p. 135, 2014.

[19] R. Chieffo, F. Giatsidis, R. Santangelo et al., "Repetitive transcranial magnetic stimulation with $\mathrm{H}$-coil coupled with cycling for improving lower limb motor function after stroke: an exploratory study," Neuromodulation: Journal of the International Neuromodulation Society, vol. 24, pp. 1-7, 2020.

[20] C. Yijie, "Effects of repetitive transcranial magnetic stimulation on spasm and motor function of lower limbs in patints with stroke," Chongqing Medical Journal, vol. 47, no. 25, pp. 3292-3298, 2018.

[21] T. Jing and W. Yan, "Long term efficacy and safety of repetitive transcranial magnetic stimulation combined with repeated injection of botulinum toxin type a in the treatment of spasticity of lower limb muscles spasm after stroke," Journal of Brain and Nervous Diseases, vol. 26, no. 5, pp. 272-276, 2018.

[22] Y. Yang, H. Lijie, C. Xiguo, C. Liushuan, and Q. Baoyan, "Effect of repetitive transcranial magnetic stimulation on limb function recovery in stroke patients with lower limb spasm," Chinese Journal of Physical Medicine and Rehabilitation, vol. 37, no. 8, pp. 602-603, 2015.

[23] H. Hua-yao, D. Hou-Wei, C. Chao, Z. Yi-xian, and C. Qing-fa, "Rehabilitative effect of low-frequency rTMS combined FES 
on lower limb spasm and motor function in patients with subacute ischemic stroke," Chinese Journal of Cardiovascular Rehabilitation Medicine, vol. 28, no. 2, pp. 134-138, 2019.

[24] S. Li and G. E. Francisco, "New insights into the pathophysiology of post-stroke spasticity," Frontiers in Human Neuroscience, vol. 9, p. 192, 2015.

[25] C. B. Ivanhoe and T. A. Reistetter, "Spasticity: the misunderstood part of the upper motor neuron syndrome," American Journal of Physical Medicine and Rehabilitation, vol. 83, no. 10 Suppl, pp. S3-S9, 2004.

[26] D. M. Miller, C. S. Klein, N. L. Suresh, and W. Z. Rymer, "Asymmetries in vestibular evoked myogenic potentials in chronic stroke survivors with spastic hypertonia: evidence for a vestibulospinal role," Clinical Neurophysiology, vol. 125, no. 10, pp. 2070-2078, 2014.

[27] A. Thibaut, C. Chatelle, E. Ziegler, M.-A. Bruno, S. Laureys, and O. Gosseries, "Spasticity after stroke: physiology, assessment and treatment," Brain Injury, vol. 27, no. 10, pp. 1093-1105, 2013.

[28] S. Naghdi, N. N. Ansari, M. Rastgoo, B. Forogh, S. Jalaie, and G. Olyaei, "A pilot study on the effects of low frequency repetitive transcranial magnetic stimulation on lower extremity spasticity and motor neuron excitability in patients after stroke," Journal of Bodywork and Movement Therapies, vol. 19, no. 4, pp. 616-623, 2015.

[29] L. Terreaux, R. Gross, F. Leboeuf et al., "Benefits of repetitive transcranial magnetic stimulation (rTMS) for spastic subjects: clinical, functional, and biomechanical parameters for lower limb and walking in five hemiparetic patients," Science World Journal, vol. 2014, Article ID 389350, 2014.

[30] D. Podsiadlo and S. Richardson, "The timed "up \& go:" a test of basic functional mobility for frail elderly persons," Journal of the American Geriatrics Society, vol. 39, no. 2, pp. 142-148, 1991.

[31] M. Kobayashi and A. Pascual-Leone, "Transcranial magnetic stimulation in neurology," The Lancet Neurology, vol. 2, no. 3, pp. 145-156, 2003.

[32] R. B. C. Dos Santos, S. C. B. Galvão, L. M. P. Frederico et al., "Cortical and spinal excitability changes after repetitive transcranial magnetic stimulation combined to physiotherapy in stroke spastic patients," Neurological Sciences, vol. 40, no. 6 , pp. 1199-1207, 2019.

[33] N. N. Ansari and S. Naghdi, "The effect of Bobath approach on the excitability of the spinal alpha motor neurones in stroke patients with muscle spasticity," Electromyography \& Clinical Neurophysiology, vol. 47, no. 1, pp. 29-36, 2007.

[34] C. P. Phadke, C. T. Robertson, E. G. Condliffe, and C. Patten, "Upper-extremity H-reflex measurement post-stroke: reliability and inter-limb differences," Clinical Neurophysiology, vol. 123, no. 8, pp. 1606-1615, 2012.

[35] N. N. Ansari and S. Naghdi, "The effect of Bobath approach on the excitability of the spinal alpha motor neurones in stroke patients with muscle spasticity," Electromyography \& Clinical Neurophysiology, vol. 47, no. 1, pp. 29-36, 2007.

[36] J. M. Hoogendam, G. M. J. Ramakers, and V. Di Lazzaro, "Physiology of repetitive transcranial magnetic stimulation of the human brain," Brain Stimulation, vol. 3, no. 2, pp. 95-118, 2010.

[37] Z. Lin and T. Yan, "Long-term effectiveness of neuromuscular electrical stimulation for promoting motor recovery of the upper extremity after stroke," Journal of Rehabilitation Medicine, vol. 43, no. 6, pp. 506-510, 2011.

[38] M. Corti, C. Patten, and W. Triggs, "Repetitive transcranial magnetic stimulation of motor cortex after stroke," American
Journal of Physical Medicine \& Rehabilitation, vol. 91, no. 3, pp. 254-270, 2012.

[39] E. H. Hoyer and P. A. Celnik, "Understanding and enhancing motor recovery after stroke using transcranial magnetic stimulation," Restorative Neurology and Neuroscience, vol. 29, no. 6, pp. 395-409, 2011.

[40] J.-P. Lefaucheur, A. Aleman, C. Baeken et al., "Evidence-based guidelines on the therapeutic use of repetitive transcranial magnetic stimulation (rTMS): an update (2014-2018)," Clinical Neurophysiology, vol. 131, no. 2, pp. 474-528, 2020.

[41] Z. Guo, Y. Jin, X. Bai et al., "Distinction of high- and lowfrequency repetitive transcranial magnetic stimulation on the functional reorganization of the motor network in stroke patients," Neural Plasticity, vol. 2021, Article ID 8873221, 2021.

[42] Y. Roth, A. Zangen, and M. Hallett, "A coil design for transcranial magnetic stimulation of deep brain regions," Journal of Clinical Neurophysiology, vol. 19, no. 4, pp. 361-370, 2002. 